Relations industrielles

Industrial Relations

\title{
Humanisation du travail
}

Volume 3, numéro 1, septembre 1947

URI : https://id.erudit.org/iderudit/1024061ar

DOI : https://doi.org/10.7202/1024061ar

Aller au sommaire du numéro

Éditeur(s)

Département des relations industrielles de l’Université Laval

ISSN

0034-379X (imprimé)

1703-8138 (numérique)

Découvrir la revue

Citer cet article

(1947). Humanisation du travail. Relations industrielles / Industrial Relations,

3(1), 7-7. https://doi.org/10.7202/1024061ar

Tous droits réservés (C Département des relations industrielles de l’Université Laval, 1947
Ce document est protégé par la loi sur le droit d'auteur. L'utilisation des services d'Érudit (y compris la reproduction) est assujettie à sa politique d'utilisation que vous pouvez consulter en ligne.

https://apropos.erudit.org/fr/usagers/politique-dutilisation/ 
augmentation générale des salaires sur le prix d'un objet quoique cela soit très difficile, puisque, comme nous l'avons vu, le main-d'oeuvre indirecte entre dans presque tous les éléments qui forment le prix. Cependant, un économiste américain de renom, M. Wassily Leontif, professeur à l'Université Harvard, dans un article publié dans «The Quarterly Journal of Economics », a calculé cette incidence en tenant compte de la structure de l'économie américaine de 1939. Nous en avons extrait le tableau suivant qui ne manque pas aussi d'intérêt.

Tableau 2: Changement de prix résultant d'un accroissement hypothétique de $10 \%$ dans les taux de salaires calculé en tenant compte de la structure de l'économie américaine de 1939. (3)

\begin{tabular}{|c|c|c|}
\hline \multirow[t]{2}{*}{ Industrie } & \multicolumn{2}{|c|}{$\begin{array}{l}\text { Changement de prix ré- } \\
\text { sultant d'un accroisse- } \\
\text { ment général des salai- } \\
\text {-- res de } 10 \%\end{array}$} \\
\hline & $\begin{array}{c}\text { Dans toutes } \\
\text { - les } \\
\text { industries }\end{array}$ & $\begin{array}{c}\text { Dans } \\
\text { l'industrie } \\
\text { concernée }\end{array}$ \\
\hline Produits chimiques....... & 4.40 & 1.92 \\
\hline Bois et papier.. & 5.20 & 3.53 \\
\hline Textile et cuir.. & 4.91 & 3.08 \\
\hline Caoutchouc .............. & 4.21 & 2.58 \\
\hline Produits alimentaires $\ldots$ & 3.23 & 1.18 \\
\hline Métaux ferreux $\ldots \ldots \ldots \ldots$ & 4.90 & 2.92 \\
\hline Fabrication de métal.... & 5.54 & 3.53 \\
\hline Construction $\ldots \ldots \ldots \ldots \ldots$ & 6.44 & 3.75 \\
\hline Transport ....... & 5.21 & 4.67 \\
\hline
\end{tabular}

Ces statistiques que nous présentons en toute objectivité ne manqueront pas d'être utiles aux employeurs, aux chef ouvriers et au public. Elles leur permettront jusqu'à un certain point de pouvoir prévoir l'incidence du coût direct et indirect de la main-d'oeuvre dans la formation des prix, et d'attribuer à chacun ses responsabilités.

(3) Massily LeONTIEF, Wages, profit and price, The Quarterly Journal of Economics, Harvard University Press, vol. LXI, No. 1, November 1946, pp. 26-40.

\section{NOS COLLABORATEURS}

Dion, Gérard, L.Th., L.Ph., M.Sc.Soc., professeur à la Faculté des sciences sociales de l'Úniversité Laval et secrétaire du Département des relations industrielles.

Poul.IN, Gonzalve, o.f.m., D.Sc.Soc., directeur des études à la Faculté des sciences sociales de l'Université Laval et directeur de l'Ecole de service social.

Tremblay, Gérard, L.Ph., sous-ministre du Travail de la province de Québec, professeur au Département des relations industrielles de l'Université Laval et directeur de ce Département.

\section{HUMANISATION DU TRAVAIL"}

C'est devenu un lieu commun enfin d'incriminer une civilisation où l'entreprise économique sans cesse accrue tourne, semble-t-il, pour ellemême, pour sa propre fin qui est le profit, usant et dévorant l'homme, tarissant la natalité aussi bien dans le prolétariat que dans la classe bourgeoise. Cette déshumanisation la condamne; et il y a longtemps qu'on a formulé le remède en demandant que l'entreprise économique travaille désormais pour la personne humaine. Mais le problème se pose aussi en termes de civilisation et de culture. Notre civilisation industrielle pose le problème de la culture, - de la culture ouvrière, d'abord, mais plus généralement de celle de lhomme industriel, qui n'est pas seulement ouvrier. Il ne s'agit pas seulement, on le comprend, d'une culture générale, humaniste et littéraire, acquise en marge de la vie de travail, pour faire contrepoids aux soucis des affaires, aux déformations professionnelles ou aux servitudes du travail manuel de l'usine. La situation de l'homme industriel moderne est liée à un certain état de la civilisation; mais puisque la vie industrielle est une vie humaine, un certain humanisme lui correspond, que doivent développer les institutions de la civilisation. La civilisation industrielle y trouvera les éléments de sa propre vie intérieure. Mais loin que ce problème soit résolu, on attend encore les analyses qui permettront d'en définir les termes.

(.) J.-T. Delos, o.p., La Nation. Vol. I., pp. 39-40.

\section{RAPPORT DU DEUXIEME CONGRÈS DES RELATIONS INDUSTRIELLES DE LAVAL}

C'est avec regret que nous ne pourrons fournir le rapport du deuxième congrès avant trois semaines. Ce retard fut occasionné par des circonstances incontrôlables d'ordre matériel et technique. Il est actuellement sous presse. Il est entendu que tous ceux qui étaient inscrits au Congrès le recevront dès sa publication. 